\title{
At the crossroads \\ Bringing the tenure and promotion process into the Digital Age
}

O ver the past two years, Grand Valley State University (GVSU) faculty librarians have been looking for ways to improve the portfolio process for personnel reviews. The personnel review system at GVSU is such that all unit faculty members are responsible for reviewing colleagues' portfolios and voting on their reappointments, tenure decisions, and promotions, meaning all tenured and tenure-track librarians must carve out a significant amount of time for this each year.

Traditionally, these portfolios have taken the format of one printed copy, available in the libraries dean's office, for review by one individual at a time. Since GVSU has libraries located in four separate locations on two campuses, this meant that about half of the reviewers needed to travel and set aside large blocks of time to review the documentation.

Given the number of individuals who may be reviewed in a given year, it became a burdensome process to review several print portfolios. In addition, a number of faculty librarians being reviewed were looking for new and better ways of presenting their work, especially digitally born materials. Due to the changing nature of the work and the desire to improve efficiency in a distributed work environment, the decision was made to move to electronic portfolios.

\section{Choosing a platform}

As is the wont of academics everywhere, a committee was formed to delve deeper into this issue. This ad hoc group was charged with investigating several different platforms, including LibGuides, Google Sites, PBWiki, and Adobe Acrobat. The committee wanted to select a product that did not have a steep learning curve for those who were less comfortable with technology. They felt the emphasis should be on the content rather than the container.

Other concerns included the ability to archive the content, sustainability of the software, potential technical problems, and privacy.

The committee narrowed their choices down to two products-Adobe Acrobat and LibGuides. The deciding factors ended up being time and comfort level. At this point, the librarians up for review only had a few months until their portfolios were due. Many librarians were unfamiliar with Adobe Acrobat, and the committee also found that getting site licenses for the product was not an easily feasible task.

In contrast, most librarians were already familiar with LibGuides and knew how to use this platform. Due to these various factors, the committee recommended LibGuides for the 2009 personnel reviews.

\section{What is LibGuides?}

LibGuides describes itself as a content management system for use by libraries to create customizable subject guides. It allows creators great flexibility in the type of content they share, including RSS feeds, audiovisual media, and interactive polls.

Laura Harris isWeb services librarian, e-mail: harlaura@gvsu.edu, Julie Garrison is director of research and instruction services, e-mail: garrisoj@gvsu.edu, and Emily Frigo is liaison librarian, e-mail: frigoe@gvsu.edu, at Grand Valley State University

() 2009 Laura Harris, Julie Garrison, Emily Frigo 
LibGuides not only offers flexibility in the type of content shared, but how the content can be arranged. In addition to linking to guides from a library's Web site, they can also be embedded anywhere on the Web.

\section{Implementation}

Traditionally, portfolios were comprised of several sections: a statement of one's professional philosophy; prose discussing one's professional effectiveness, scholarly and creative output, and service, respectively; evidence; and supporting documents, including annual reports, curriculum vitae, and position descriptions. As mentioned above, these portfolios were then stored in the dean's office, and a lengthy appeal process was required should a person under review want to add anything to his or her portfolio.

The move to an electronic format caused some logistical issues not originally anticipated by the aforementioned committee. The portfolio creators struggled with issues of how to organize the content of the portfolios, as well as how and where to store files that represented the supporting documents. Eventually, each librarian made his or her own decisions on how to represent this information.

Another unanticipated issue was how to ensure edits would not be made to the portfolios after their due date. It was decided that after the electronic portfolios were completed, the GVSU administrator of LibGuides transferred ownership of the portfolio LibGuides to the library's Designated United Head.

The guides were marked as private within the LibGuides system, meaning that only those people who had been provided the URL to the guides or those with LibGuide logins would be able to view them.

\section{Evaluation}

To determine how well the new online portfolio process worked and whether librarians should continue to use LibGuides for this purpose, a survey of both portfolio creaters and reviewers was conducted. Cre- ators were asked how they liked the online process, whether they thought LibGuides was a suitable portfolio platform, and how this compared to a paper portfolio they had created in the past.

Similarly, reviewers were asked to describe the benefits and drawbacks of reviewing portfolios online, how this process compared to reviewing paper portfolios, and how they would feel about creating an online portfolio in the future.

The survey was sent to the 26 librarians and faculty who participated in the review process. Eighteen responses were received. Seven responses were from individuals who both created and reviewed portfolios. The other 11 responses were from individuals who only reviewed portfolios.

\section{How did it work for the creators?}

Seven faculty created portfolios and responded to the survey. While the survey responses were overwhelmingly positive about creating online portfolios, frustrations were also expressed. Many mentioned the ease with which connections could be made between different sections of the portfolio and the benefit of being able to include digitally born content without having to make paper copies.

Creators noted that there was a great deal of freedom and flexibility in designing and structuring the individual portfolio. On the other hand, it may have provided too much freedom, as one portfolio creator commented, "It took me a few tries to figure out how best to create the connections between different aspects of the portfolio." This same person commented that "overall I was pleased with the outcome."

The five faculty members who had not created portfolios before, as they were up for the first reviews, found the process to be more open. This group enjoyed discussing portfolio structure with others, and found it easy to share drafts.

It should be noted that we believe this group may have looked more favorably upon the process because they were instru- 
mental in orchestrating these changes, from the decision of what platform to use to the creation to the review.

At least one individual who had created a print portfolio prior to this review cycle felt that formatting an electronic portfolio was a drawback and mentioned, ". . many people wanted to use a style of formatting typical of Web sites and of LibGuides. I thought this was not appropriate for a portfolio format so I tried to maintain a typical paper format."

The only other drawback that was mentioned was one comment regarding repeating material throughout the portfolio. That person also commented that this was not due to the online format but had to do with the portfolio guidelines.

When asked how creators liked using LibGuides specifically, the majority mentioned that they liked the format. For most, the biggest drawback was security, as anyone who had a username and password with LibGuides was able to see the portfolios.

For those who had created a paper portfolio in the past, we asked how the process compared. One thought the online format was better and the other preferred the paper portfolio, stating that it took less time to create and provided a more standardized format.

\section{How did it work for the reviewers?}

Overwhelmingly, the librarians preferred reading online portfolios to reading print portfolios. They noted that the ease of access was one of the greatest benefits; they could read the portfolios from any computer with an Internet connection, and at any time. A few people noted the ease of rereading parts of or entire portfolios, both prior to and during the in-person personnel meetings.

Reviewers also commented that the portfolios were generally well-organized and easy to navigate-something that might be attributed to the fact that many of the librarians had used LibGuides extensively for its intended purpose.

Still, the process was not without its drawbacks. Some of the concerns expressed

\section{There was strong support from librarians to continue creating online portfolios; most librarians would prefer to use LibGuides, since they are already familiar with it, but several expressed willingness to use something similar.}

by the committee were echoed by the reviewers: namely, concerns about the technology. It is unknown whether LibGuides will continue to be a successful product; it is also unknown whether the library will continue to have a subscription to LibGuides, even if it does remain successful.

Some librarians also had concerns about the privacy of LibGuides; some were concerned that anyone with a login to the system (including students and staff who edit and maintain guides) would be able to view the portfolios.

Others commented on the lack of consistency of the portfolios. It is our opinion that these concerns are justified, and would likely arise no matter what platform was used. Three people complained of eyestrain.

Some people reported printing some parts of the portfolios to read them offline; these people generally printed the supporting documents, such as annual reports, curriculum vitae, and some evidence. However, those who printed a portion of material were in the minority, at 22 percent.

There was strong support from librarians to continue creating online portfolios; most librarians would prefer to use LibGuides, since they are already familiar with it, but several expressed willingness to use something similar.

\section{Conclusion}

Overall, there is a strong desire to continue using electronic portfolios, and although there is general support to keep using LibGuides, there is still some debate whether this platform is the best option. There are some concerns about varying experience with the technology and ability to adequately archive content. To make this process more 


\section{... there is a hesitancy to develop guidelines, which may restrict the creativity expressed in the portfolios; as a group, the librarians struggle to find a balance between standardization and creative freedom.}

inclusive, librarians going through the next review cycle will now be able to choose between Adobe Acrobat or LibGuides.

It seems that the discussion of which electronic "container" is used for the portfolios has kindled a more complex conversation about the content of the portfolios.

Many questions have been raised both in the survey responses and in other faculty discussions: How should evidence and narrative be linked? Should there be a standard template or specific stylistic guidelines to follow? What evidence should be narrated or compiled into a bulleted list? and What relationship do the portfolios have to the librarians' annual activity reports?

Although the librarians seek answers to these questions, there is a hesitancy to develop guidelines, which may restrict the creativity expressed in the portfolios; as a group, the librarians struggle to find a balance between standardization and creative freedom. However, articulated guidelines might provide the necessary structure to help make this process less work intensive.

For now, librarians who are more comfortable with a narrative format will likely choose Adobe Acrobat, while those librarians more conversant with principles of information architecture may gravitate toward using LibGuides. In some sense, the library is still standing at a crossroads with an eye in either direction. $\boldsymbol{n}$

\section{("Assignment Research Calculator" continues from page 459)}

found in each step. Our provost, library dean, Development Office, and other staff frequently promote the ARC to the campus and local community.

We feel the ARC has helped to foster awareness of the library and our many services to students, and we hope to be able to document this in the future through our feedback and assessment measures.

\section{Acknowledgments}

This project would not have been possible without funding from a CSU Information Literacy grant awarded to Monica Fusich from the California State University Chancellor's Office, CSU Fresno Foundation Grant Agreement no. 60040, and the technical expertise of Anish Dutta, graduate IT student, Instruction and Outreach Services Department.

\section{Notes}

1. Sourceforge.net, "Assignment Calculator," sourceforge.net/projects/assign-calc/ (accessed July 28, 2009).
2. The Assignment Research Calculator, csufresno.edu/library/ARC2/index.php (accessed July 28, 2009).

3. California State University-Fresno, Institutional Research, Assessment, and Planning, "IRAP Data and Research," www.csufresno. edu/irap/data/index.shtml (accessed July 28, 2009).

4. ACRL, "Introduction to Information Literacy," www.pla.org/ala/mgrps/divs /acrl/issues/infolit/overview/intro/index. cfm.

5. ACRL, "Information Literacy Competency Standards for Higher Education," www.ala.org/ala/mgrps/divs/acrl /standards/informationliteracycompetency. cfm.

6. About the ARC, csufresno.edu/library/ ARC2/about_us.shtml.

7. ACRL, "Information Literacy Competency Standards for Higher Education, Use of the Standards," www.ala.org/ ala/mgrps/divs/acrl/standards/ALA_print _layout_1_185693_185693.cfm\#useofst. $\boldsymbol{n}$ 